\title{
16 USING THE MISSION CRITICAL MARKET DIFFERENTIATING (MCMD) MODEL TO IMPROVE BUSINESS AND INFORMATION TECHNOLOGY AGILITY
}

\author{
Niel Nickolaisen \\ Headwaters Inc. \\ South Jordan. Utah U.S.A.
}

\begin{abstract}
The mission critical/market differentiating (MCMD) model focuses organizational resources on processes, products, and projects that will best meet and respond to market demands. Conversely, the MCMD model can help organizations reduce resource expenditures in areas that are neither mission critical nor market differentiating.

This model was initially designed to assure information technology solutions focused on the needs of the customer and had the greatest return on invested capital. In a broader organizational application, the MCMD model helps organizations

- identify which activities deserve their best attention and focus (i.e., pick which battles they should be fighting)

- simplify and streamline their operational processes

- limit the scope of projects and over-building of their underlying features
\end{abstract}

\section{INTRODUCTION}

Over the past several years, companies have become disenchanted with technology solutions that do not deliver business value. They have outsourced key competitive processes, launched technology projects that far exceeded their planned budgets but did not deliver expected functionality, forgone investments in off-the-shelf software, and become jaded to the newest application or hardware sales pitch. Unfortunately, this has not kept us from trying to build a better technology mouse trap that creates competitive advantages in a continually changing marketplace and that captures market share by meeting the continuous escalation of customer expectations. The problem facing many 
companies, therefore, is to discover a way to deliver the technology they need while not over-building or over-complicating the technology and the business activities the technology supports. If companies cannot find such a balance, they risk limiting their ability to respond to market changes.

The answer, found in the mission critical/market differentiating (MCMD) model, is that internal information technology systems need to become more focused on business priorities and be more adaptable to the changing marketplace demands. However, this is difficult if our internal, operational processes are bureaucratic and get in the way of our ability to prioritize and adapt. Also, if our focus is too diffused, we might not allocate our best thinking and resources on the activities that will differentiate us in the marketplace.

\section{THE MCMD MODEL}

The MCMD model is a four-quadrant diagram that classifies products, processes, and projects (and their underlying features) as either high or low for two main categories: mission critical and market differentiation.

Mission critical: The degree to which our activities and processes are essential to our ability to deliver our products and services and operate as an organization.

Market differentiating: The degree to which our activities and processes help us gain market share and enter new markets.

Figure 1 is a graphical representation of this quadrant.

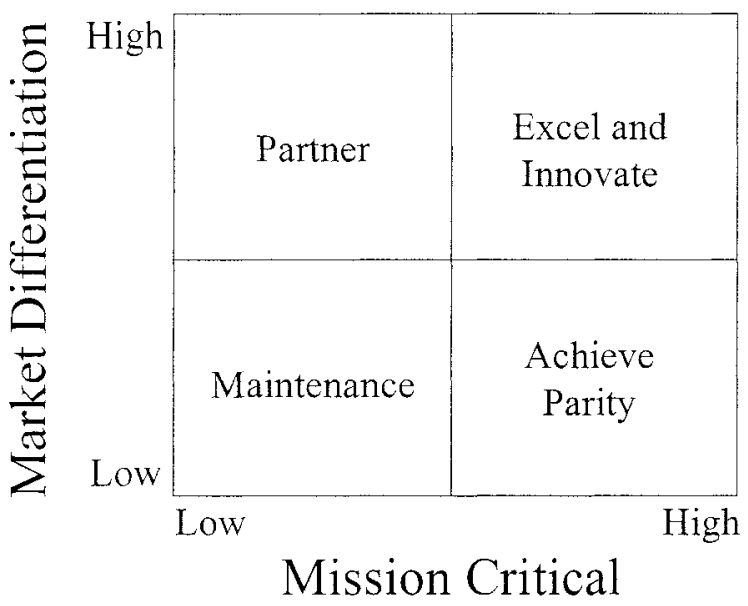

Figure 1. The MCMD Model 
The quadrants are defined as

- Excel: High for both mission critical (MC) and market differentiating (MD). These are the activities that we use to gain market share, define our market value proposition, and enter new markets. Examples include product development and market and customer analysis.

- Parity: High MC, low MD. These are the bulk of our activities. We must perform these activities because they are critical to our mission or operations. If we perform these activities poorly, we do harm. Examples include customer billing and production planning.

- Partner: High MD but low MC. These are activities that do or could differentiate us in the marketplace but that we do not have to perform ourselves. Intel chips inside of Dell computers are a good example; neither would do well to try and enter the other's strategic niche, but building a partnership provides great return on investment.

- Maintenance: Low MC and low MD. These activities have no meaningful connection to our operations or our markets. Examples include office cleaning services and our user name standards. Someone may have to pay attention to these details but it is not very important to the strategic initiatives of the company.

\section{THE METHODOLOGY}

We start by defining the criteria we will use to segregate our activities into the four types. We then filter all of our activities through the criteria and onto the appropriate box. In some cases, activities will straddle boxes. That is all right as long as we know which activity components lay in which box. In practice, I use the model to first identify the activities that belong in the market differentiating and mission critical box. I then know that everything else falls into one of the other boxes (and most likely most fall into the mission critical but not differentiating box) and I use that information to make generalized judgments about how I will manage these activities.

After assigning our activities to their appropriate boxes, I assume that the goal or purpose of each activity is associated with its box as shown in Figure 2.

I want to ensure that I am "best-in-class" at my market differentiating and mission critical activities. These are the battles I choose to fight. I focus my best thinking, talent, and resources on these activities. I learn how to continually innovate and improve these activities and their results (I have to continually innovate and improve these activities as, over time, they move to a different box).

The goal of my mission critical but not differentiating activities is to achieve and maintain parity with the market. Doing anything more than achieving and maintaining parity with the market implies that I am over-investing in these activities (which, in addition to the poor value this provides, carries an opportunity cost: I am spending my valuable thinking, talent, and resources unnecessarily). These activities are prime candidates for simplification and standardization. In fact, I optimize my business agility the more I simplify and standardize these activities. I need to perform these activities well but I also need to ensure that they do not get in the way of my responding to the dynamics of the marketplace. 


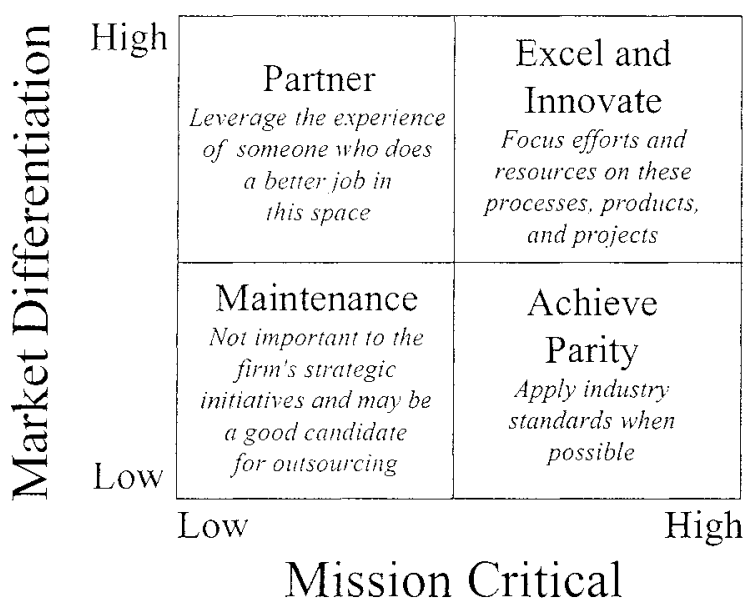

Figure 2. Aligning Activities with Goals

The differentiating but not mission critical activities give me the opportunity to partner with someone for whom these activities are differentiating and mission critical. I should exploit this opportunity as this also increases my agility.

It matters little how I handle the neither differentiating nor mission critical activities. In fact, I should invest as little thinking, talent, and resource in these activities as possible.

\section{EXAMPLES AND RESULTS}

\subsection{Software Development}

I used the MCMD model and methodology to dramatically accelerate and simplify a large software development project. The project was initially designed to build a document collaboration and management system supporting the drafting and submission of financial documents (annual reports, 10 -K statements, investment memoranda, etc.). The initial technical requirements document defined over 7,000 function points, a budget of $\$ 2$ million, and a development time line of 18 months. The filtering criteria were defined and the functional requirements mapped onto the MCMD. This resulted in identification of two differentiating components and 27 parity components.

A conscious choice to reuse or license existing technologies for the parity components and allocate thinking, talent, and resources on the two differentiating components was made. This resulted in a development plan of 240 function points (rather than over 7,000), a budget of $\$ 350,000$ (rather than $\$ 2$ million), and a time line of 4 months (rather than 18 months). Using this model not only reduced the cost and time of the project but also focused the company on the functionality that now and in the future make this a superior product. 


\subsection{Enterprise Software Selection and Implementation}

I have also applied the MCMD model to the selection, implementation, and support of enterprise software like enterprise requirements planning systems. For most companies, ERP functionality supports mission critical but not differentiating activities (like purchasing, inventory management, financials, order management, etc.). This being the case, an ERP selection and implementation project should assume an implementation with no (i.e., zero) customizations. Customizing the business applications that support parity activities implies over-investment in these activities (as customization requires thinking, talent, and resources). In addition, customizing the business applications that support parity activities implies that these customizations will need to be revised or rebuilt in order to respond to changing market conditions.

As an example, I used the MCMD model and methodology to reduce the budget and timeline for an ERP selection and implementation project from $\$ 4.4$ million and 3 years to $\$ 2.2$ million and 4 months. Approaching the project this way also accelerated the company's development of its technology to support its differentiating activities. Rather than having its resources tied up for a 3 -year ERP project, it was able to shift the resources much earlicr to its differentiating technology.

\section{USING THE MODEL AND METHODOLOGY TO IMPROVE AGILITY}

I believe that in order to be adaptive to changing market conditions (many driven by advances in and the use of technology) two things must be done.

- First, fight the right battles. By this I mean allocate our thinking, talent, and resources to those activities that will improve our market position.

- Second, simplify all of our other activities. This serves us in at least two ways. First, it frees up our thinking, talent, and resources to fight the right battles. Second, it ensures that these activities will not get in the way of our ability to respond to market changes.

By using the above model and methodology, we learn how to properly allocate our thinking, talent, and resources. In addition, once we have determined that the goal of an activity is to achieve or maintain parity, we have created a context that we can use, both strategically and tactically, to simplify how we perform the activity.

As an example, I recently used this model to significantly simplify the credit-tocollections process for a wholesaler/retailer. This company had developed over 30 different types of customer accounts. We ran all of the financial management processes through the model and determined that the goal of the customer credit process was to achieve and maintain market parity. We could not find any examples where parity translated into multiple account types. Rather, because this wholesaler/retailer had two principal customer types (wholesale and retail) we collapsed the more than 30 different account types into two (one for wholesale customers and one for retail customers). Inside each of these two types of accounts, customers were either good (paid their bills and paid them on time) or bad (did not pay their bills or did not pay them on time). This 
simple structure allowed the wholesaler/retailer to simplify its credit department and allocate its resources to activities that could provide differentiation.

\section{CAVEATS}

I have used the MCMD model in multiple situations, both simple and complex. The real challenge in adopting the model is a cultural challenge. Both departments and people have a natural inclination to ensure that their business activities are classified as differentiating. Including the mission critical dimension in the model helps reduce this tendency (but does not eliminate it). Additionally, I have found that using the MCMD model to filter activities and then align resource allocation with the results of the filtering is a significant change from how resources are traditionally assigned to activities and initiatives. To pull off changes of this type and magnitude requires leadership and a solid change-management plan. The MCMD model only helps create the context for changing and simplifying activities.

\section{SUMMARY}

The MCMD model allows the firm to allocate its resources to products, processes, and projects in an appropriate manner. Decisions at all levels of the operation are now focused on the market and the firm's mission and the appropriate response to each level of mission criticality and market differentiating. Likewise, and perhaps even more importantly it allows a discussion within the firm about the opportunities for strategic improvements and an agile/adaptive approach to future changes.

\section{ABOUT THE AUTHOR}

Niel Nickolaisen has held technology executive $(\mathrm{ClO})$ and operations executive (COO) positions in large- and medium-sized enterprises, typically in turnaround roles. He is expert in the rapid/adaptive selection, implementation, and deployment of enterprise business applications, analysis tools, and systems. He has developed a strategic and tactical alignment model that results in significantly improved returns on technology and business initiatives (by both improving the benefits and reducing the costs and risks).

Niel has in-depth knowledge of enterprise management technologies, enterprise resource planning applications, and storage management tools. He holds two patents for enterprise management tools. He is past president of the Intermountain Chapter of the Society for Information Management. He holds an M.S. in Engineering from the Massachusetts Institute of Technology and a B.S. in Physics from Utah State University. He was named IT Executive of the Year at the 2004 Gartner Research Mid-Sized Enterprise Summit.

Niel can be reached at nnickolaisen@hdwtrs.com. 